\title{
on_education
}

Journal for Research and Debate

\section{the shifting rhythms of academic work}

\author{
Fabian Cannizzo
}

\begin{abstract}
Popular rhetoric surrounding the transformation of academia around the globe often draws on a set of dichotomous discourses, characterising organisational change as inciting a clash or struggle between opposing conceptions of the academy and its workers: scientific versus corporate values; collegial versus managerial work control; fast versus slow productivity; instrumental versus substantive goals; and high modern versus post-modern knowledge orders. Here, I seek to narrow in on a key battleground for the politics of academia, namely the temporal ordering of scholarly work.
\end{abstract}

\section{Dichotomies in Academic Work}

Popular rhetoric surrounding the transformation of academia around the globe often draws on a set of dichotomous discourses, characterising organisational change as inciting a clash or struggle between opposing conceptions of the academy and its workers: scientific versus corporate values (Winter, 2009); collegial versus managerial work control (Parker \& Jary, 1995); fast versus slow productivity (Berg \& Seeber, 2017; Pels, 2003); instrumental versus substantive goals (Osbaldiston et al., 2016); and high modern versus post-modern knowledge orders (Delanty, 2001). Here, I seek to narrow in on a key battleground for the politics of academia, namely the temporal ordering of scholarly work. The perception that academic workers are under more pressure than in the past and that this pressurisation is leading to widespread negative consequences has become near doxic among critical higher education scholars. This paper outlines the politics at the heart of time ordering in academia, which I describe as a chronopolitics of academic work (Vostal, 2016, p. 170ff).

I offer an alternative way of approaching the chronopolitics of academic work through elaborating on a key assumption within much of the current literature: that broad social transformations to the policy and organisational infrastructure of global academia have a deterministic relationship with academic work temporalities, hence producing dichotomies such as scientific/corporate values and fast/slow spaces. I seek to problematise the assumption that neoliberal and managerial interventions into the organisation of academic life have systemic, logically-inferable influences over the temporal experience of academic work. In place of this widespread inference, I advocate for empirical scrutiny of the relationship between policy infrastructures, managerial programs for intervening in academic productivity, and the responses that academics produce within a transforming work environment. By focusing on the socialisation of academics to time-management practices, scholarly work can begin to describe how academic staff become complicit in the reproduction of timescapes felt to produce undesirable consequences.

Chronopolitics - Time is Political 
The study of academic work temporalities has been underscored by an often-repeated dichotomisation of temporal experiences that can roughly be designated as the 'fast' - deemed to properly belong to the realm of capitalism and ensuing economic rationalities - and the 'slow', which is the purview of science, bureaucracies, and the idealised academic Lebensführung, or ethical lifestyle choices (Abel \& Cockerham, 1993; Vostal et al., 2018). Like with all dichotomies, each concept is relational, bifurcating, and hence a means of limiting analytic focus to a boundary within social life. Contemporary examples of the fast/slow dichotomy include: Oili-Helena Ylijoki and Hans Mäntylä's (2003) four-part typology of scheduled time and contracted time (both of which are harrying, pressurised orders) against timeless time and personal time (both of which exist beyond time pressure); Dick Pels' (2003) bifurcation of the "slow turnover" appropriate to scientific culture against the "fast thinking" of the broader competitive fields of power and economics; and my colleagues' and my own (Osbaldiston et al., 2016) ideal-type categories of time ordering in academia, split between purposeful substantive rational times and efficiency-driven instrumental rational times. This dichotomisation is helpful in devising ideal-type categories of kinds of behaviour and action in academia, although it must be borne in mind that these descriptions are not value-free but rather the product of interested actors, who are themselves part of the domains that they are describing.

Despite not always being concerned with the varying speeds of life (cf. Sorokin \& Merton, 1937, 1990), the study of sociotemporalities became inflected with the long-standing belief that academic life is and ought to exist beyond the worlds of economics, politics, and popular media. In Homo Academicus, Bourdieu defends the autonomy of the scientific field, claiming that the cultural hierarchy of "scientific and intellectual renown" competes against the broader social hierarchy of "economic and political capital" (Bourdieu, 1998, p. 48). This competition between hierarchies links them in a temporal economy, or - as Bourdieu (1998, p. 95) claims - the political and economic advantages that form "academic power can only be accumulated and maintained at the cost of constant and heavy expenditure of time". Investment in bureaucratic power therefore tends "to compromise the accumulation of a capital of scientific authority and vice versa" (Bourdieu, 1998, p. 96). Dick Pels has pointed out that Bourdieu's apparently neutral descriptions of the field of intellectual struggle lack a degree of self-reflexivity, whereby they fail to acknowledge that they are in fact part of that field of struggle. In attempting to define the intellectual field and its sociologic, Bourdieu presents "performative definitions that (re)describe their object in such a manner that the description simultaneously (re)creates what it purports to describe" (Pels, 2003, p. 117). Pels embraces this performativity, describing scholarly autonomy as producing a "self-interested science" (2003, p. 112) that is distinguished from other domains of life by its unique anti-politics and anti-economics, thereby justifying the slow/fast dichotomy in the study of academic times.

A central performative category in the production of a chronopolitics is that of craftwork (Cannizzo forthcoming). In their polemic The Slow Professor, Berg and Seeber (2016, p. 17) claim that the time pressures in contemporary universities are "detrimental to intellectual work, interfering with our ability to think critically and creatively". This sentiment is of ten repeated within the slow university literature, centring cognitive and communicative temporalities in academic work. The moral evaluation of the craftsperson present in C. Wright Mills' (1959) account of academic work in the appendix to The Sociological Imagination resonates with common assumptions about science and scholarship as time-consuming and "unhastened" (Pels, 2003) practices. Hence, claims that academic work requires standards set by the academic profession are not merely descriptive, but often performative statements through which academic work routines and control are contested and legitimated. With the control of labour placed at the centre of analysis, the dichotomisation of 
temporalities into faster/slower categories is revealed as a political tactic.

From Acceleration to Managerial Fabrications

The idea that academic work is "slow work" harmed by the acceleration of modernity (Rosa, 2013) is a counter-factual generalisation, as scientific discovery and educational work are both temporally complex. Vostal et al. (2018) have recently begun to map these complexities, noting that scientific production contains a mixture of temporal dynamics that require scientists to engage in "agentic synchronization" to conduct knowledge work successfully (p. 17). Scientific work is unpredictable: discoveries are produced unreliably and of ten irregularly; scientists' expectations of their work shift over time; and scientific work is negotiated among several actors existing within their own temporal norms. Teaching and learning may similarly require long trials of testing and revising methods and assumptions before a reliable curriculum and means of communication are established between the educator and student, given that the latter exist within their own socially-differentiated timescapes (Bennett \& Burke, 2017). However, national performance and productivity measurement mechanisms require the standardisation of time to produce comparisons. The production of performances is central to "the translation of complex social processes and events into simple figures or categories of judgement" (Ball, 2003, p. 217).

Stephen Ball (2003) describes the transformation of public education into a metrically-governed enterprise as facilitated by three intertwined policy technologies: "the market, managerialism and performativity" (p. 215). Like much subsequent work on academic performance and metrics, Ball focuses on the disciplinary consequences of productivity measures, which he describes as "fabrications". Describing these measures as such is significant because it signals to the open recognition - by managers, employees, and often media personnel - that they are selective representations. The shared knowledge that fabrications are selective forms of knowing - combined with the meta-knowledge that each party knows about the other's knowledge of this selectivity produces what Elliot has described as "pathologies of creative compliance in the form of gamesmanship". Being more than a disciplinary culture, fabrications "conceal as much as they reveal" about the conditions of work (Ball, 2003, p. 225), producing space for agentic, discretionary action between the process/object being measured and the fabrication that alleges to represent it. Put simply, for many academic duties, there is no task manager leaning over your shoulder or forewoman ensuring that you are conducting the correct bodily motions associated with work flow or rhythm. Hence, descriptions of the acceleration of scholarly work (Vostal, 2016) must either take account of the role played by academics themselves in producing the self-governance necessary for predictable work rhythms or else describe how idiosyncractic habits results in acceleration.

Many academic socialisation and time-management practices are not reducible to an effect of managerial productivism. Academic blogging is a widespread practice that is still largely beyond the ordinary institutional performance measuring and monitoring of universities. In an analysis of 100 academic blogs, Mewburn and Thomson (2013) found that blogs were often directed towards persons with similar interests to the author, suggesting that rather than reflecting a means of communicating with the "general public" (i.e. Bourdieu's speedy field of media) there exists "a loose academic blogging community of practice" (p. 1114) with the characteristics of a "virtual staffroom" (p. 1116) or "conversational scholarship" (Gregg, 2006; Carrigan, 2016). While academic blogging can be used to create a heightened scholarly profile, Mewburn and Thomson claim that bloggers are more often engaged in a "gift economy" of exchange without the expectation of reward (p. 1115). 
Academic writing groups similarly escape the evaluative measures and rewards systems within universities, although they are often used by participants as opportunities to create timemanagement habits (Myatt et al., 2014). However, the design and uses of writing groups are not singularly productivist. The emergence of seemingly productivity-focused writing groups is a case in point. In addition to writing sprints, the now popular Shut Up and Write! (SUAW) sessions also include time for socialisation, which Mewburn describes as "the key 'informal learning space' as it allows the exchange of ideas and thoughts about workplace practice, that is, 'shop talk" (Mewburn et al., 2014, p. 410). Through SUAW, participants work together to communally produce anxiety, relief and joy. Rather than merely exposing scholars to a pre-existing logic of acceleration, these spaces allow for agentic experimentation with different rhythms, paces, senses of pressure and relief, social and technological infrastructures.

Towards the Diachronic Study of Academic Work

The study of socialisation (which is always a process-based view of social order) invites diachronic analysis back into focus within the study of social life. When conceptualised synchronically as part of a social structure of power relationships, temporality is reduced to a factor of structure itself. In the case of growing managerialism within universities, harried working practices are seen as a logical outcome of the imposition of the efficiency principle upon the structure of work. However, a focus on how academics develop time-management practices reveals the procedural development and reproduction of managerial norms, which require the agency of academics.

A greater understanding of how everyday, routinised procedures for organising work and life activities are reconciled with other orders of time - including lifetime (Rosa, 2013, p. 8) - would place agency back at the centre of analyses of academic work and living. Rather than reifying time management under the power structure of managerial governance - in which the 'fast' times of productivity, media and economics are juxtaposed to the 'slow' times of thinking, learning and crafting - we might instead ask what practices academics find to cope with the myriad expectations, hopes and commitments made of their bodies and presence. The answers found might not necessarily entail competition between different conceptions of time, but rather the development of a skillset that Vostal et al. (2016) describe as "agentic synchronisation" or Erikson and Mazmanian (2017) call "temporal entrepreneurship", rather than a retreat into an "oasis of deceleration" (Rosa, 2013, p. xxxvii). Such a perspective may help to identify how performative descriptions of academic "productivity" intersect with the socialisation of academics and the development of timemanagement practices. The aim here is to bring the diachronic properties of social processes back into focus within the study of academic work.

\section{References}

Abel, T., \& Cockerham, W. C. (1993). Lifestyle or Lebensführung? Critical Remarks on the Mistranslation of Weber's “Class, Status, Party". The Sociological Quarterly, 34(3), 551-556.

Ball, S. J. (2003). The Teacher's Soul and the Terrors of Performativity. Journal of Education Policy, 18(2), 215-228.

Berg, M., \& Seeber, B. K. (2017). The Slow Professor: Challenging the Culture of Speed in the Academy. Toronto, ON: University of Toronto Press.

Bennett, A., \& Burke, P. J. (2017). Re/conceptualising Time and Temporality: An Exploration of Time in Higher Education. Discourse: Studies in the Cultural Politics of Education, published online first. 
DOI: https://doi.org/10.1080/01596306.2017.1312285

Bourdieu, P. (1988). Homo Academicus. P. Collier (trans.). Stanford, CA: Stanford University Press.

Cannizzo, F. (forthcoming) Academic Craftwork: On Authenticity and Value in Academia. In

Cannizzo, F., \& Osbaldiston, N. (Eds.), The Social Structures of Global Academia. Milton Park: Routledge, in press.

Carrigan, M. (2016). Social Media for Academics. London: Sage.

Delanty, G. (2001). Challenging Knowledge: The University in the Knowledge Society. Buckingham: The Society for Research into Higher Education and Open University Press.

Gregg, M. (2006). Feeling Ordinary: Blogging as Conversational Scholarship. Continuum, 20(2), 147-160.

Mewburn, I., Osborne, L., \& Caldwell, G. (2014). Shut Up \& Write! Some Surprising Uses of Cafés and Crowds in Doctoral Writing. In Aichison, C., \& Guerin, C. (Eds.), Writing Groups for Doctoral Education and Beyond: Innovations in Theory and Practice (pp. 399-425). London and New York: Routledge.

Mewburn, I., \& Thomson, P. (2013). Why do Academics Blog? An Analysis of Audiences, Purposes and Challenges. Studies in Higher Education, 38(8), 1105-1119.

Mills, C.W. (1959). The Sociological Imagination. Oxford: Oxford University Press.

Myatt, P., Edwards, A., \& Bird, F. (2014). Achieving Greater Productivity with a Peer Writing Group. In Proceedings of the Australian Conference on Science and Mathematics Education, $140-148$.

Osbaldiston, N., Cannizzo, F., \& Mauri, C. (2016). 'I Love My Work but I Hate My Job' - Early Career Academic Perspective on Academic Times in Australia. Time and Society, online first.

DOI: https://doi.org/10.1177/0961463X16682516

Parker, M., \& Jary, D. (1995). The McUniversity: Organization, Management and Academic Subjectivity. Organization, 2(2), 319-338.

Pels, D. (2003). Unhastening Science: Autonomy and Reflexivity in the Social Theory of Knowledge. Liverpool: Liverpool University Press.

Rosa, H. (2013). Social Acceleration: A New Theory of Modernity. Trejo-Mathys, J. (trans.) New York: Colombia University Press.

Sorokin, P., \& Metron, R. (1937, 1990). Social-time: A Methodological and Functional Analysis. In Hassard, J. (Ed.), The Sociology of Time (pp. 56-66). New York: Palgrave Macmillan.

Vostal, F. (2016). Accelerating Academia: The Changing Structure of Academic Time. Houndmills, Basingstoke: Palgrave Macmillan.

Vostal, F., Benda, L., \& Vortová, T. (2018). Against Reductionism: On the Complexity of Scientific Temporality. Time and Society, online first. DOI: https://doi.org/10.1177/0961463X17752281

Winter, R. (2009). Academic Manager or Managed Academic? Academic Identity Schisms in Higher Education, 31(2), 121-131.

Ylijoki, O.-H., \& Mäntylä, H. (2003). Conflicting Time Perspectives in Academic Work. Time and Society, 12(1), 55-78.

Zerubavel, E. (1981, 1985). Hidden Rhythms: Schedules and Calendars in Social Life. Berkeley, LA and London: University of California Press.

\section{Recommended Citation}

Cannizzo, F. (2018). The Shifting Rhythms of Academic Work. On Education. Journal for Research and Debate, 1(3). https://doi.org/10.17899/on_ed.2018.3.3 
Do you want to comment on this article? Please send your reply to editors@oneducation.net. Replies will be processed like invited contributions. This means they will be assessed according to standard criteria of quality, relevance, and civility. Please make sure to follow editorial policies and formatting guidelines.

\section{fabian cannizzo}

Dr. Fabian Cannizzo is a sociologist in Melbourne, Australia, with expertise in the sociology of academia and the creative industries. He is presently publishing The Social Structures of Global Academia (Routledge, 2019) with Nick Osbaldiston. You can find more info or contact him through his blog www.thesocialthinker.wordpress.com or on Twitter @fabiancann 